\title{
The association between coffee intake and breast cancer risk: a meta-analysis and dose-response analysis using recent evidence
}

\author{
Yilun Li, Li Ma \\ Department of Breast Center, The Fourth Hospital of Hebei Medical University, Shijiazhuang, China \\ Contributions: (I) Conception and design: All authors; (II) Administrative support: All authors; (III) Provision of study materials or patients: All \\ authors; (IV) Collection and assembly of data: All authors; (V) Data analysis and interpretation: All authors; (VI) Manuscript writing: All authors; (VII) \\ Final approval of manuscript: All authors. \\ Correspondence to: Li Ma. Department of Breast Center, The Fourth Hospital of Hebei Medical University, No. 169 Tianshan Street, Yuhua District, \\ Shijiazhuang, China. Email: mali_kr@163.com.
}

\begin{abstract}
Background: To assess the association between coffee intake and breast cancer risk using data from studies published during the past 15 years.

Methods: Articles published between January 2005 and May 2020 were collected from PubMed, Embase, and Web of Science databases, and the Cochrane library. Coffee consumption was set as the exposure factor of breast cancer risk, and relative risk (RR) was set as the assessment indicator. Random-effects or fixed-effects models were used for the meta-analysis, depending on the level of heterogeneity. The linear and non-linear dose-response relationship was assessed using the generalized least-squares method and restricted cubic spline model. Articles were evaluated by sensitivity analysis, and Begg's and Egger's tests and funnel plots were used to evaluate publication bias. The process of meta-analysis referred to Meta-analyses of Observational Studies in Epidemiology (MOOSE).
\end{abstract}

Results: We retrieved 26 relevant studies in the dose-response analysis and meta-analysis. A negative correlation was found between coffee consumption and breast cancer risk (RR: 0.95; 95\% CI: 0.92-0.99). A linear and marginal dose-response relationship was found for six case-control studies (RR: 0.98; 95\% CI: $0.95-1.00$ ) and 10 cohort studies (RR: 0.98; 95\% CI: 0.97-1.00). Subgroup analysis showed that the relationship between coffee consumption and breast cancer risk was moderated by menstrual status and geographic region.

Conclusions: Overall, the meta-analysis found a negative correlation between coffee intake and breast cancer risk, especially in postmenopausal and European women.

Keywords: Coffee; breast cancer; dose-response; meta-analysis

Submitted Sep 30, 2020. Accepted for publication Jan 18, 2021.

doi: 10.21037/apm-20-1962

View this article at: http://dx.doi.org/10.21037/apm-20-1962

\section{Introduction}

Breast cancer is the most common type of malignancy in females (1). According to According to Ahmad, breast cancer statistics, breast cancer is the leading cancer among women, and the morbidity and mortality are increasing year by year (2). Certain factors affect the risk of breast cancer. One study shows that a high body mass index (BMI) is positively associated with the risk of breast cancer (3).
Another study reports that women who have fewer children or have not breastfed have a higher risk of breast cancer (4). However, there remain some factors contributing to breast cancer that require elucidation.

It is thought that coffee, a common item consumption, may reduce the risk of type 2 diabetes mellitus and Parkinson's disease (5). Polyphenols and diterpenoids in coffee have been reported to have anti-inflammatory, antioxidant, and apoptotic properties (6). The consumption 
of coffee has also been weakly associated with cardiovascular and cancer mortality (7), and it has been found that the daily consumption of coffee may reduce the recurrence rate of breast cancer (8).

Several studies have assessed the relationship between coffee and breast cancer risk, mainly using extreme intake or dose-response calculations (9-11). A meta-analysis of 20 case-control studies and 17 cohort studies calculated a relative risk (RR) of 0.97 (95\% CI: 0.93-1.00), and a linear relationship was established for coffee consumption and breast cancer risk, which decreased by $2 \%$ for every two cups consumed per day (12). A concurrent meta-analysis of 16 cohort studies and 10 case-control studies found a marginally significant correlation between coffee and breast cancer (RR: 0.96; 95\% CI: 0.93-1.00) (13). A more recent dose-response meta-analysis of 21 cohort studies found that in post-menopausal women, drinking four cups of coffee per day could reduce the risk of cancer by $10 \%$ (RR: 0.90; 95\% CI: $0.82-0.99)$ (14). These data imply that coffee may exert a protective effect in some populations. However, the results of some recent studies, which were not included in these meta-analyses, contradict their outcomes. One study, for example, shows that instant coffee has a positive association with breast cancer risk (15), and another study shows that coffee and/or caffeine increases the risk of breast cancer among premenopausal or normal weight women (16). It is therefore necessary for us to include more recent studies in an analysis of the association between coffee and breast cancer risk. Recent case-control and cohort studies now enable us to perform subgroup analyses for menstrual status, BMI, and regional variance, as well as to compare their findings with those of older meta-analyses. We analyzed the literature on coffee consumption and breast cancer from the past 15 years to update the evidence for any association and to identify factors affecting this relationship. We present the following article in accordance with the PRISMA reporting checklist (available at http://dx.doi. org/10.21037/apm-20-1962).

\section{Methods}

\section{Search strategy}

We searched the PubMed, Embase, and Web of Science databases, and the Cochrane library, and limited the search to the period from January 2005 to May 2020. Keywords used in the search were "coffee", "caffeine", and "breast cancer". To be eligible, a study had to meet the following criteria: (I) it was a case-control or cohort study; (II) it was conducted in humans; (III) the exposure of interest was coffee or caffeine; (IV) the outcome of interest was breast cancer; (V) the published data included RR, odds ratio or hazard ratio values after adjusting for confounders, and a corresponding confidence interval that could be extracted or calculated. The process of meta-analysis made reference to Meta-analyses of Observational Studies in Epidemiology (MOOSE).

\section{Data extraction}

The following information was extracted from each included study: first author's last name, study design, case source or country where the study was conducted, followup duration, number of cases and subjects, adjustment for potential confounders, and coffee intake and the corresponding RR, odds ratio or hazard ratio, and $95 \% \mathrm{CI}$ after adjusting for confounders from included studies. For each study, the minimum coffee consumption was set as the reference value for analysis, and the maximum coffee consumption was used as the exposure factor.

\section{Assessment of study quality and risk of publication bias}

The Newcastle-Ottawa Scale (NOS) evaluates study quality and the risk of bias from the selection of cases and controls, the comparability of cases and controls, and the ascertainment of exposure and non-response rates. We used the NOS for observational studies to assess the quality of the studies. Since the adjustment of different covariates in different included studies may affect the heterogeneity, we performed a subgroup analysis on the adjustment of different covariates, and the influence of each factor on the relationship between coffee consumption and breast cancer was verified by subgroup analysis (Table 1). For the measurement of coffee, in the dose-response meta-analysis, we used the regular coffee cup as the unit of measurement, and converted different measurement units into consistent units to reduce method heterogeneity. A sensitivity analysis was performed by excluding one study at a time to see whether this resulted in significant changes to the findings. A funnel plot, the Begg method, and the Egger's test were used to assess publication bias.

\section{Statistical analysis}

$\mathrm{RR}$, odds ratio, or hazard ratio for all coffee consumption 
Table 1 Pooled measures of the association of coffee intake and breast cancer

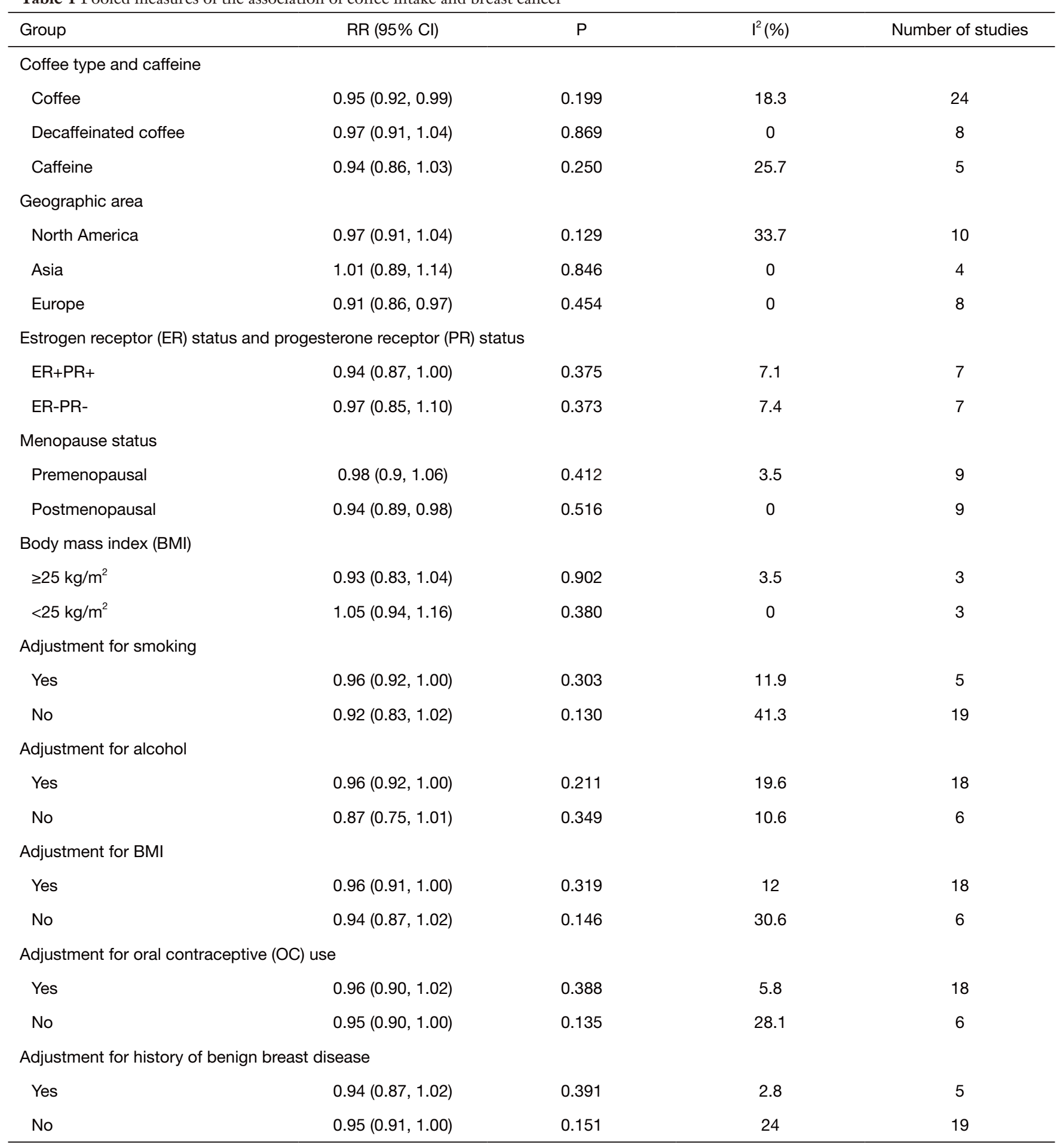

Relative risk (RR) in a random effects model was used for subgroup analysis. $\mathrm{P}$ value represents heterogeneity. 


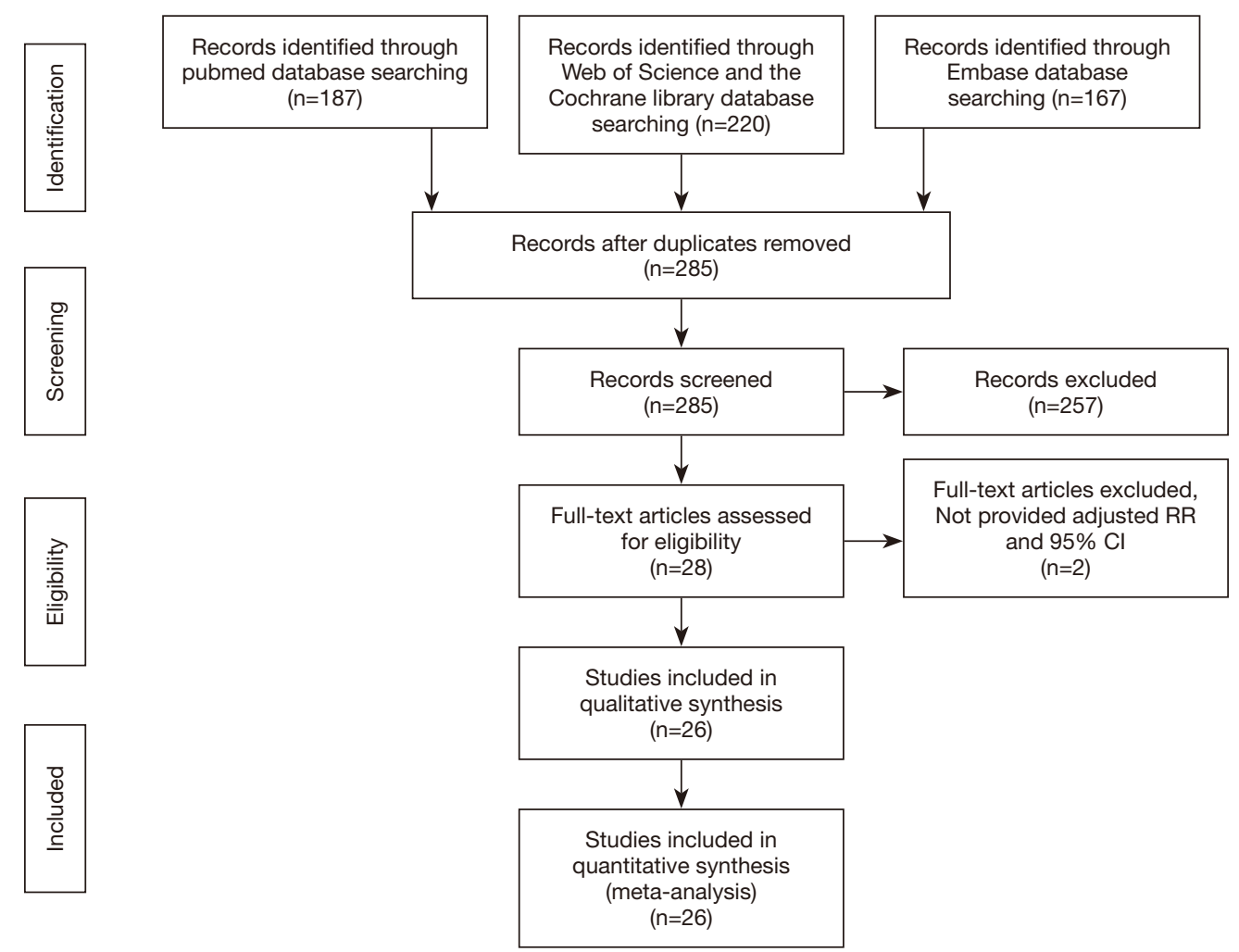

Figure 1 Flow chart of study selection. RR, relative risk; CI, confidence interval.

categories and breast cancer were extracted from each study. The RR and hazard ratio were considered equivalent measures of risk, and the odds ratio in case-control studies could also be approximated by the RR $(17,18)$. The heterogeneity of effects between different studies was assessed by an $\mathrm{I}^{2}$ statistical test or Q test, in which $\mathrm{I}^{2}>50$ or $\mathrm{P}<0.1$ for the $\mathrm{Q}$ test indicated significant heterogeneity. The random-effects model was used to analyze the effect values, taking into account the differences between the inside and outside of the study.

We also evaluated the dose-response relationship between coffee intake and breast cancer. We assigned the midpoint of the upper and lower boundaries in each category as the range of average intake. If the lower or upper boundary for the lowest and highest category, respectively, was not reported, we assumed that the boundary had the same amplitude as the closest category. The generalized least-squares method proposed by Greenland and Longnecker was used for dose-response analysis $(19,20)$. In the first stage, the potential link between coffee intake and breast cancer risk was investigated by the restricted cubic spline model of four-section fixed-percentile
(5\%, 35\%, 65\%, and 95\%) exposure distribution (21). In the next stage, the variance/covariance matrix and specific estimates (standard errors) were evaluated. The overall meaning of the curve was assessed by examining the joint effects of spline transformations. The $\mathrm{P}$ value of the nonlinear curve was calculated using the null hypothesis of the second spline coefficient, which was equal to zero (12). All analyses were performed in Stata 14.0 (StataCorp, College Station, TX, USA); glst, xbls, and related packages were used for the analysis and graphing of the dose-response data.

\section{Results}

\section{Article search and study characteristics}

The search returned 285 articles from PubMed, Embase, and Web of Science databases and the Cochrane library, of which 257 were excluded (Figure 1). After the full texts of the 28 remaining articles were read, two were excluded for not providing a corrected RR value. Table 2 lists the detailed characteristics of the final 26 articles that were included in the meta-analysis and dose-response analysis. All 26 articles measured coffee consumption, and five also 


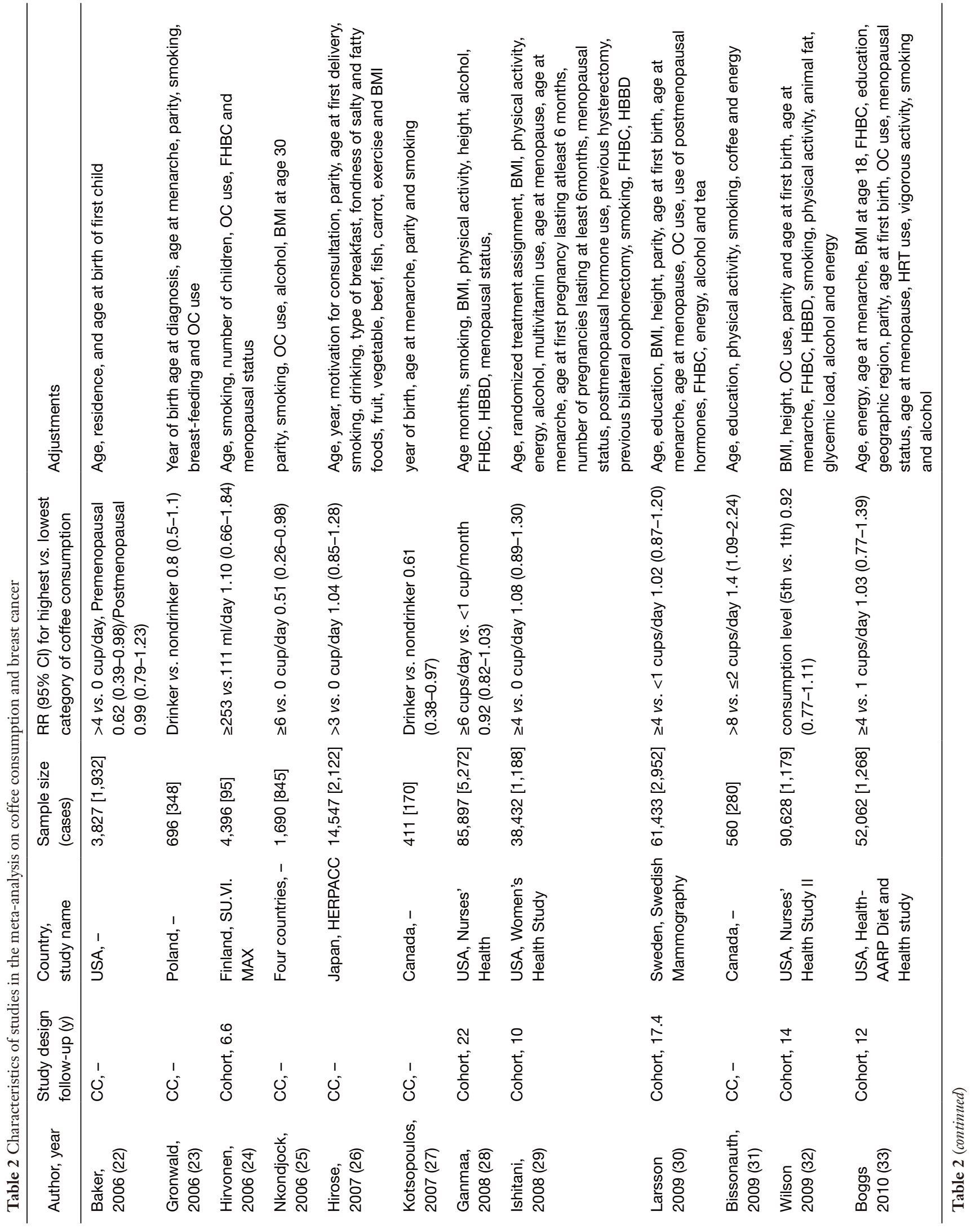




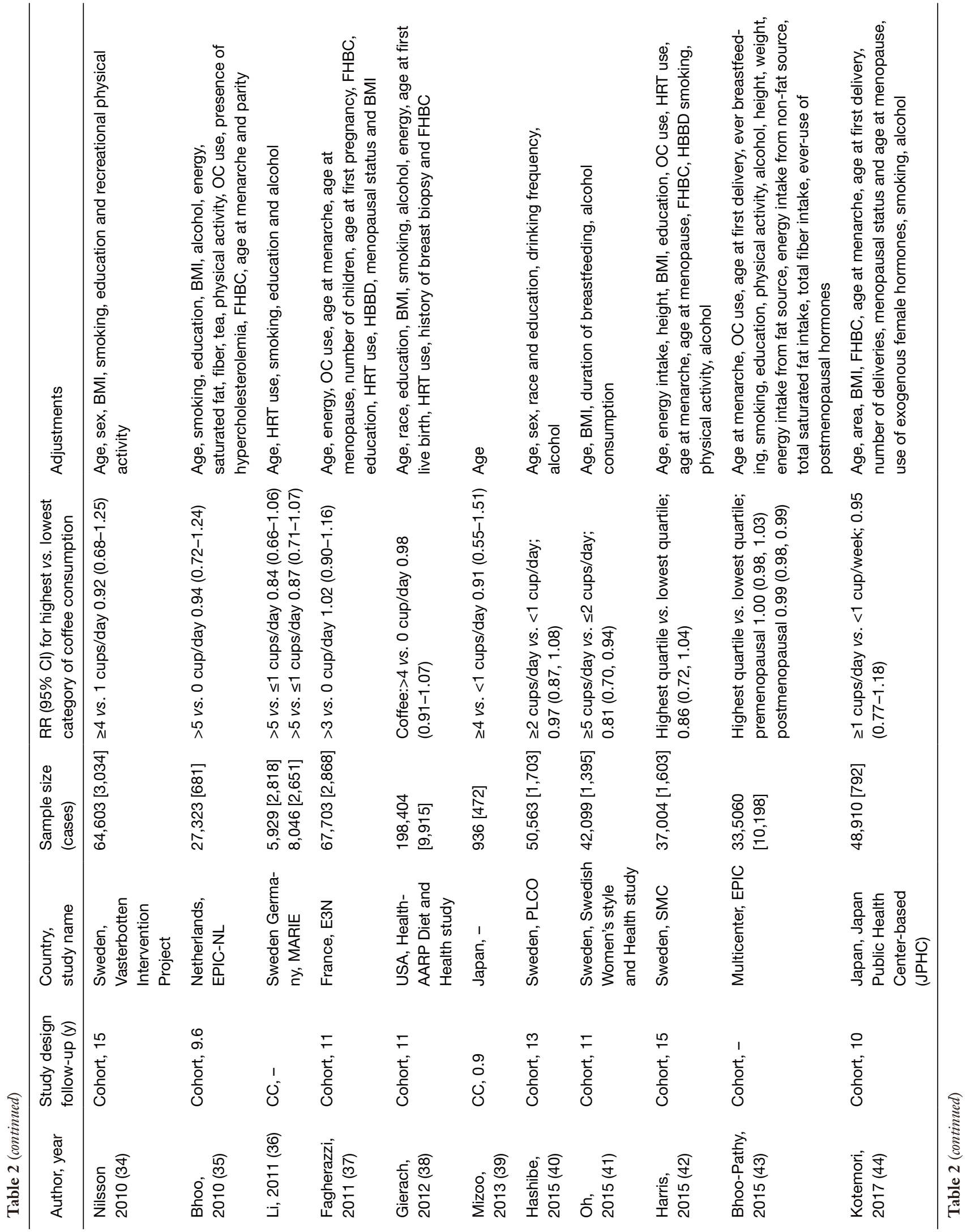


measured caffeine intake $(29,33,40,41,45)$. Nine were casecontrol studies $(15,22,23,25-27,31,36,39)$, and 17 were cohort studies.

\section{Summary RR for the highest vs. lowest level of coffee consumption}

As the EPIC study (43) included two study populations $(35,37)$, we used it to analyze the relationship between coffee intake and breast cancer; the two populations were used only in the dose-response analysis. The overall RR for breast cancer of the highest $v s$. lowest coffee consumption categories was 0.95 (95\% CI: 0.92-0.99), with low heterogeneity $\left(\mathrm{I}^{2}=18.3 \%, \mathrm{P}=0.199\right)$ (Figure 2).

\section{Subgroup analysis by population}

We performed a stratified analysis by beverage type, geographic location, estrogen and progesterone receptor expression, menstrual status, and BMI (Table 1). In hierarchical analyses, coffee consumption and breast cancer risk were significantly and negatively correlated in European cohorts (RR: 0.91; 95\% CI: 0.86-0.97) and in postmenopausal women (RR: 0.94; 95\% CI: 0.89-0.98). No significant correlations were observed for other regions or for estrogen or progesterone receptor status, BMI, or beverage type.

\section{Subgroup analysis by covariate}

We also adjusted for the categorical covariates of smoking, alcohol consumption, use of oral contraceptives, and history of benign breast disease, and performed a stratified analysis (Table 1). No significant correlations were observed, with low to moderate inter-study heterogeneity $\left(\mathrm{I}^{2}<50 \%\right)$.

\section{Dose-response analysis}

Ten cohort studies were analyzed for dose-response relationships (28-30,33-35,37,38,41,46), with a pooled total of 26,868 cases of breast cancer. A linear relationship between coffee intake and breast cancer was observed (Figure 3, non-linear $\mathrm{P}=0.76$ ). For every two cups of coffee consumed per day, the risk of breast cancer decreased by 2\% (RR: 0.98 ; 95\% CI: 0.97-1.00). The non-linear model (Figure 4) yielded similar results. Six case-control studies were also assessed $(22,25,26,31,37,39)$, with 10,090 pooled cases of breast cancer (Figure 5, non-linear $\mathrm{P}=0.88$ ). In this 


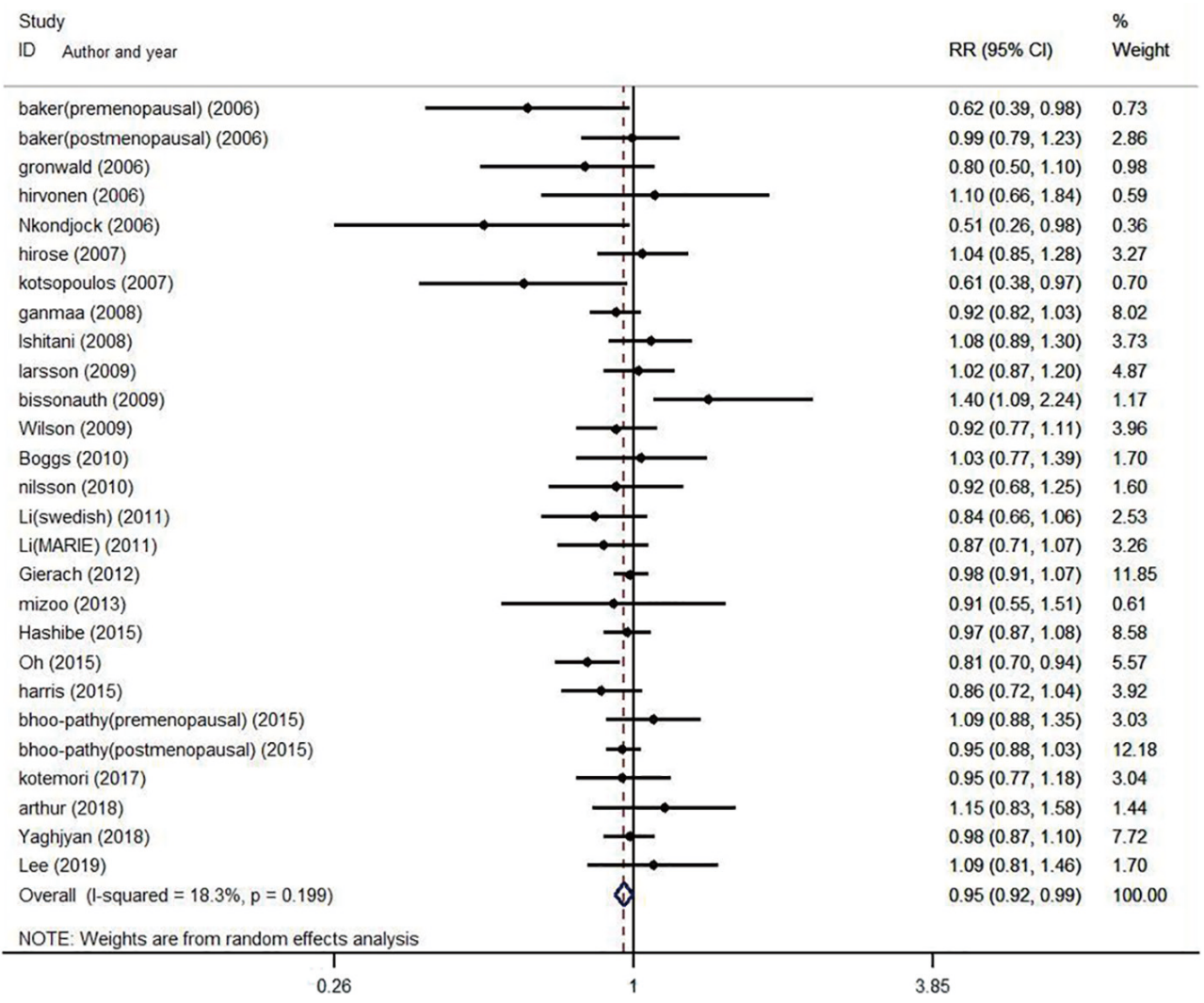

Figure 2 Multivariate-adjusted risk of breast cancer in the highest vs. lowest categories of coffee intake. CI, confidence interval; RR, relative risk.

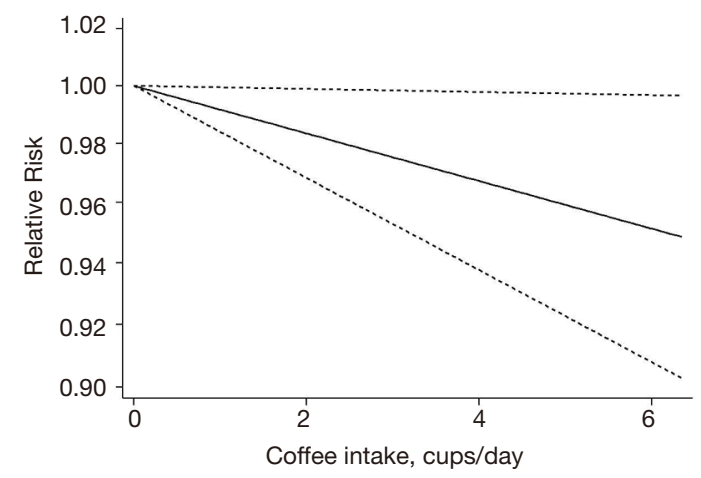

Figure 3 Relationship between coffee intake and breast cancer risk in a linear model (cohort study design).

analysis, for every two cups of coffee consumed per day, the risk of breast cancer decreased by $2 \%$ (RR: $0.98 ; 95 \%$ CI: 0.95-1.00). The results of the non-linear model (Figure 6) were similar. In summary, the case-control and cohort studies yielded consistent findings.

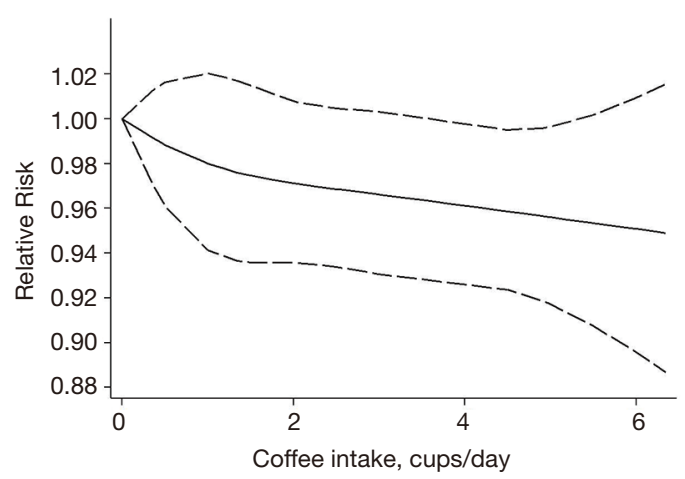

Figure 4 Relationship between coffee intake and breast cancer risk in a non-linear model (cohort study design).

\section{Study evaluation}

All of the included studies were of high quality, according to the NOS. The sensitivity analysis (Figure 7) showed that no individual study had an excessive impact on the findings. The funnel plot (Figure 8) and Egger's test (Figure 9) found 


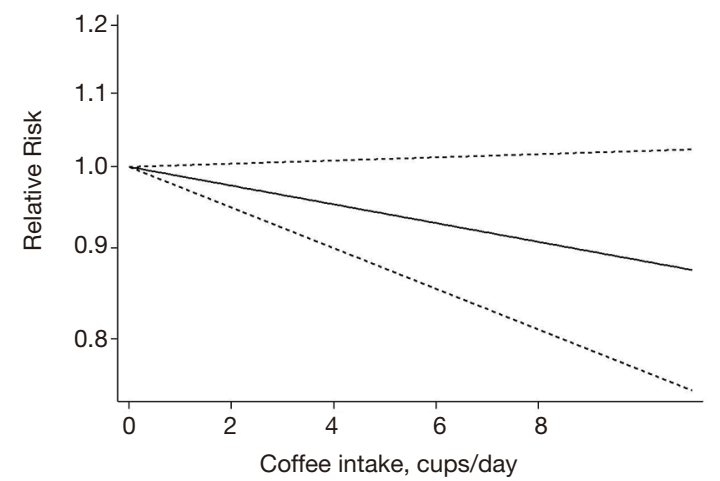

Figure 5 Relationship between coffee intake and breast cancer risk in a linear model (case-control study design).

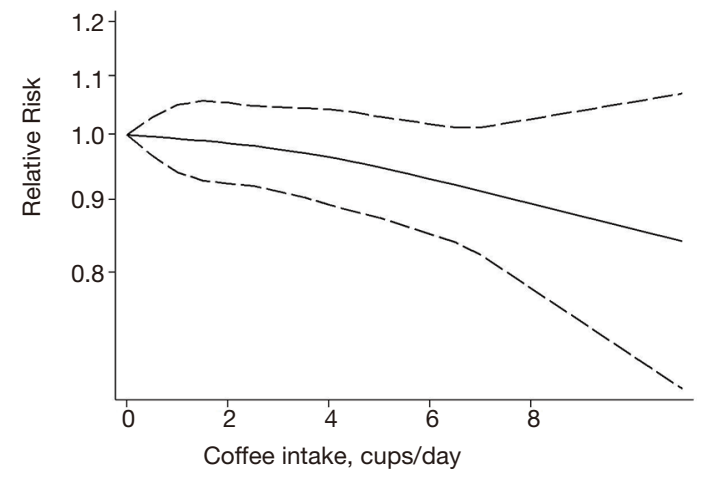

Figure 6 Relationship between coffee intake and breast cancer risk in a non-linear model (case-control study design).

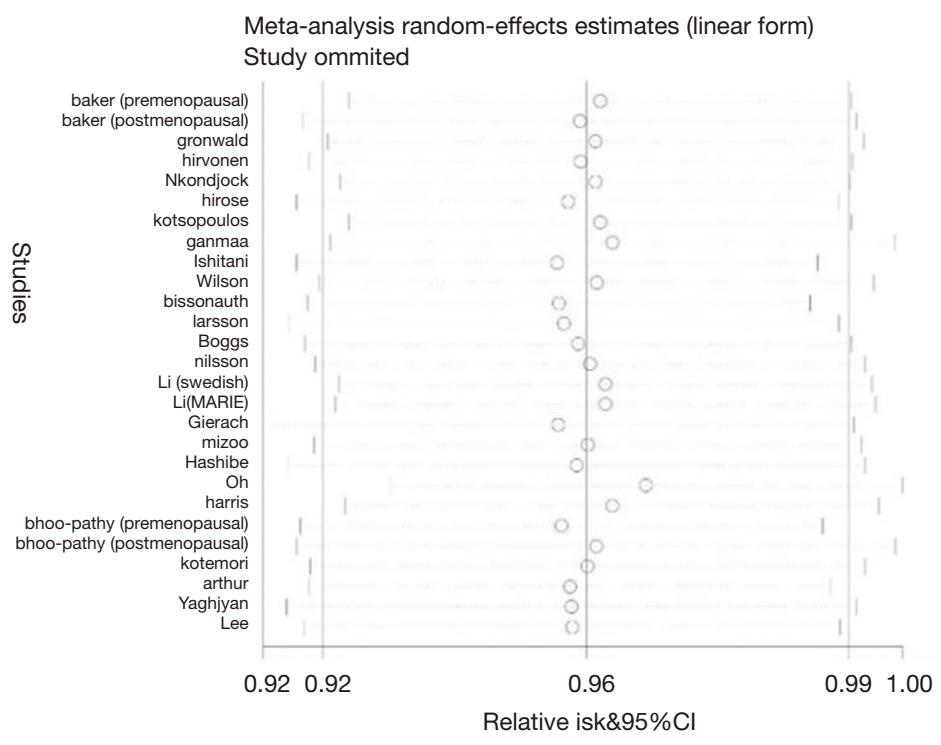

Figure 7 Sensitivity analysis (random effects model).

no significant publication bias in the analysis (Egger's test: $\mathrm{P}=0.78$; Begg method: $\mathrm{P}=0.75$ ).

\section{Ethical approval}

Ethical approval was not applicable because we did not undertake any clinical research in this study, but only collected data from available publications.

\section{Discussion}

Our meta-analysis found that coffee consumption is correlated with lower breast cancer risk (RR: 0.95; $95 \%$
CI: $0.92-0.99)$. This conclusion is similar to that of two previous assessments $(13,14)$ but differs slightly from that of a third (12). Li et al. reported an association between coffee consumption and breast cancer risk in women with estrogen receptor-negative breast cancer (13), but this was not confirmed in our meta-analysis of up-to-date data. We found a negative correlation in postmenopausal women, which is similar to the analysis of Lafranconi et al. (14).

In the dose-response analysis, we found a significant linear and marginal dose-response relationship between breast cancer risk and coffee intake, in agreement with the findings of Lafranconi et al. for both cohort studies and case-control studies (14). 


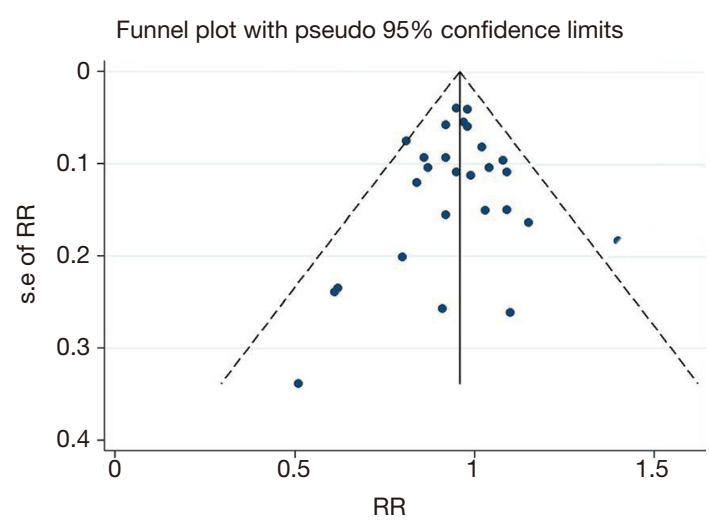

Figure 8 Funnel plot with pseudo 95\% confidence limits. CI, confidence interval; RR, relative risk.

Coffee contains caffeine, terpenes, and polyphenols. Polyphenols and terpenes are known to exert antioxidant effects; phenols from coffee extracts have been shown to selectively kill breast cancer cells without affecting normal immune lymphocytes (47). The phenol chlorogenic acid in coffee and the onset of breast cancer have also been linked: a large cohort study found that intake of phenolic acid subtypes (such as hydroxycinnamic and hydroxybenzoic acid), triterpenoids, and monoterpenes in coffee was negatively correlated with the incidence of breast cancer (48). Phenols in coffee have been reported to augment DNA repair following damage from reactive oxygen species (49).

Regarding the relationship between coffee intake and breast cancer risk before and after menopause, our metaanalysis showed that coffee intake and breast cancer incidence were negatively correlated in postmenopausal women. The effect of menstrual status on breast cancer risk may be related to interaction between caffeine and free estradiol in premenopausal women (50-52). Sex hormonebinding globulin is a major carrier of estradiol, and high levels of sex hormone-binding globulin (which reduces free estrogen levels) in postmenopausal women have been associated with a reduction in breast cancer risk $(52,53)$. At the same time, caffeine intake induces the activity of cytochrome P450 CYP1A enzymes. CYP1A2 is known to be involved in the pathogenesis of breast cancer and in estrogen metabolism $(54,55)$. Some constituents of coffee are involved in the inhibition of aromatase, which promotes the generation of estrogen (50). Circulating free estrogen has been shown to be an important contributor to breast cancer (56).

Regarding geographic distribution, our meta-analysis

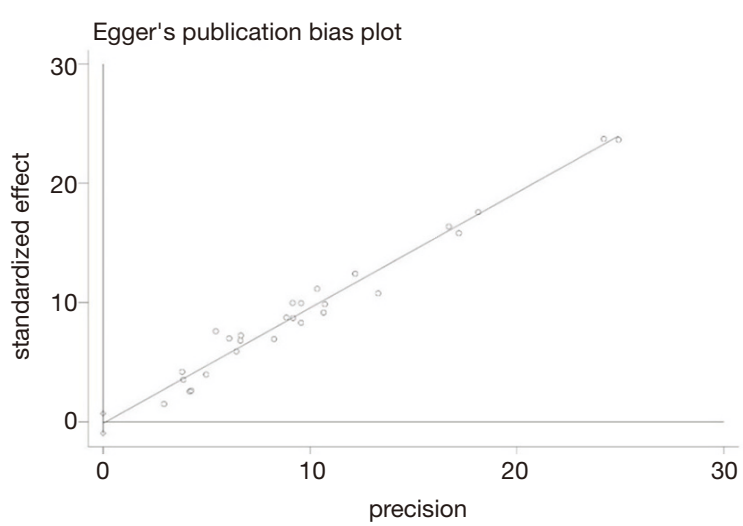

Figure 9 Egger's test of publication bias.

found that in European cohorts, coffee intake and breast cancer risk were significantly negatively correlated. The analysis did not support such a relationship in Asian and North American women, contrasting with the findings of a previous meta-analysis (12). The per capita consumption of coffee has been reported to be higher in European countries than in other regions; this especially applies to northern countries such as Finland, Sweden, Iceland, Norway, Denmark, and Austria, exceeding six kilograms annually (57). We speculate that differences in intake may affect the risk of breast cancer.

We found no correlation with BMI, although obesity has been linked to breast cancer. Obesity may affect the levels of circulating free estradiol, contributing to the pathogenesis of breast cancer (56). Estrogen has been linked to DNA damage and the stimulation of blood vessels, promoting tumorigenesis (58). Coffee may reduce the risk of cancer, cardiovascular disease, and type 2 diabetes due to its antioxidative effects and influence on estrogen levels $(59,60)$. However, the incidence of breast cancer has been linked to levels of leptin, which is involved in the JAK/STAT, MAPK, and PI3K pathways and tumor cell-related proliferation. Activation of leptin has been shown to promote the incidence, development, growth, and metastasis of breast cancer $(58,61)$. Leptin also interacts with the signaling of insulinlike growth factor 1, which promotes breast cancer cell invasion by activating epidermal growth factor receptor (62). A cross-sectional study reported a negative correlation between coffee intake and leptin levels (63); a coffeeinduced reduction in leptin levels may therefore modulate the incidence of breast cancer.

Lifestyle factors such as smoking, alcohol consumption, and use of oral contraceptives or a history of benign breast 
disease did not affect the relationship between coffee intake and breast cancer risk in our meta-analysis. Although our study updates the existing evidence with more recent data, it has certain limitations. Conclusions were consistent between data from case-control and cohort studies, but there were fewer case-control studies that could be included in the dose-response analysis.

In addition, many potentially relevant factors, such as the impact of $B R C A$ gene mutations, could not be analyzed because of the paucity of data.

\section{Conclusions}

Our meta-analysis found a weak negative correlation between coffee intake and breast cancer risk, especially in postmenopausal women. Geographical location may also affect the relationship; thus, this requires further study.

\section{Acknowledgments}

We thank Liwen Bianji, Edanz Group China (www. liwenbianji.cn/ac), for editing the English text of a draft of this manuscript. And we thank Hua Li for the guidance of statistical analysis.

Funding: None.

\section{Footnote}

Reporting Checklist: The authors have completed the PRISMA reporting checklist. Available at http://dx.doi. org/10.21037/apm-20-1962

Conflicts of Interest: Both authors have completed the ICMJE uniform disclosure form (available at http://dx.doi. org/10.21037/apm-20-1962). The authors have no conflicts of interest to declare.

Ethical Statement: The authors are accountable for all aspects of the work in ensuring that questions related to the accuracy or integrity of any part of the work are appropriately investigated and resolved.

Open Access Statement: This is an Open Access article distributed in accordance with the Creative Commons Attribution-NonCommercial-NoDerivs 4.0 International License (CC BY-NC-ND 4.0), which permits the noncommercial replication and distribution of the article with the strict proviso that no changes or edits are made and the original work is properly cited (including links to both the formal publication through the relevant DOI and the license). See: https://creativecommons.org/licenses/by-nc-nd/4.0/.

\section{References}

1. Siegel RL, Miller KD, Jemal A. Cancer statistics, 2019. CA Cancer J Clin 2019;69:7-34.

2. Ahmad A. Breast Cancer Statistics: Recent Trends. Adv Exp Med Biol 2019;1152:1-7.

3. Escala-Garcia M, Morra A, Canisius S, et al. Breast cancer risk factors and their effects on survival: a Mendelian randomisation study. BMC Med 2020;18:327.

4. Babiker S, Nasir O, Alotaibi SH, et al. Prospective breast cancer risk factors prediction in Saudi women. Saudi J Biol Sci 2020;27:1624-31.

5. Grosso G, Godos J, Galvano F, et al. Coffee, Caffeine, and Health Outcomes: An Umbrella Review. Annu Rev Nutr 2017;37:131-56.

6. Oh SH, Hwang YP, Choi JH, et al. Kahweol inhibits proliferation and induces apoptosis by suppressing fatty acid synthase in HER2-overexpressing cancer cells. Food Chem Toxicol 2018;121:326-35.

7. Grosso G, Micek A, Godos J, et al. Coffee consumption and risk of all-cause, cardiovascular, and cancer mortality in smokers and non-smokers: a dose-response metaanalysis. Eur J Epidemiol 2016;31:1191-205.

8. Lemanne D, Maizes V. Advising Women Undergoing Treatment for Breast Cancer: A Narrative Review. J Altern Complement Med 2018;24:902-9.

9. Alicandro G, Tavani A, La Vecchia C. Coffee and cancer risk: a summary overview. Eur J Cancer Prev 2017;26:424-32.

10. Malerba S, Turati F, Galeone C, et al. A meta-analysis of prospective studies of coffee consumption and mortality for all causes, cancers and cardiovascular diseases. Eur J Epidemiol 2013;28:527-39.

11. Yang TO, Crowe F, Cairns BJ, et al. Tea and coffee and risk of endometrial cancer: cohort study and meta-analysis. Am J Clin Nutr 2015;101:570-8.

12. Jiang $\mathrm{W}, \mathrm{Wu} Y$, Jiang $X$. Coffee and caffeine intake and breast cancer risk: an updated dose-response meta-analysis of 37 published studies. Gynecol Oncol 2013;129:620-9.

13. Li XJ, Ren ZJ, Qin JW, et al. Coffee consumption and risk of breast cancer: an up-to-date meta-analysis. PLoS One 2013;8:e52681.

14. Lafranconi A, Micek A, De Paoli P, et al. Coffee Intake Decreases Risk of Postmenopausal Breast Cancer: A Dose- 
Response Meta-Analysis on Prospective Cohort Studies. Nutrients 2018;10:112.

15. Lee PMY, Chan WC, Kwok CC, et al. Associations between Coffee Products and Breast Cancer Risk: a CaseControl study in Hong Kong Chinese Women. Sci Rep 2019;9:12684.

16. Arthur R, Kirsh VA, Rohan TE. Associations of coffee, tea and caffeine intake with risk of breast, endometrial and ovarian cancer among Canadian women. Cancer Epidemiol 2018;56:75-82.

17. Bradburn MJ, Deeks JJ, Berlin JA. Much ado about nothing: a comparison of the performance of meta-analytical methods with rare events. Stat Med 2007;26:53-77.

18. Higgins JP, Thompson SG, Deeks JJ. Measuring inconsistency in meta-analyses. BMJ 2003;327:557-60.

19. Greenland S, Longnecker MP. Methods for trend estimation from summarized dose-response data, with applications to meta-analysis. Am J Epidemiol 1992;135:1301-9.

20. Orsini N, Bellocco R, Greenland S. Generalized Least Squares for Trend Estimation of Summarized DoseResponse Data. Stata J 2006;6:40-7.

21. Ying $H$, Jianping $C$, Jianqing $Y$, et al. Cognitive variations among vascular dementia subtypes caused by small-, large-, or mixed-vessel disease. Arch Med Sci 2016;12:747-53.

22. Baker JA, Beehler GP, Sawant AC, et al. Consumption of Coffee, but Not Black Tea, Is Associated with Decreased Risk of Premenopausal Breast Cancer. J Nutr 2006;136:166-71.

23. Gronwald J, Byrski T, Huzarski T, et al. Influence of selected lifestyle factors on breast and ovarian cancer risk in BRCA1 mutation carriers from Poland. Breast Cancer Res Treat 2006;95:105-9.

24. Hirvonen T, Mennen LI, de Bree A, et al. Consumption of Antioxidant-Rich Beverages and Risk for Breast Cancer in French Women. Ann Epidemiol 2006;16:503-8.

25. Nkondjock A, Ghadirian P, Kotsopoulos J, et al. Coffee consumption and breast cancer risk amongBRCA1 andBRCA2 mutation carriers. Int J Cancer 2006;118:103-7.

26. Hirose K, Niwa Y, Wakai K, et al. Coffee consumption and the risk of endometrial cancer: Evidence from a casecontrol study of female hormone-related cancers in Japan. Cancer Sci 2007;98:411-5.

27. Kotsopoulos J, Ghadirian P, El-Sohemy A, et al. The CYP1A2 genotype modifies the association between coffee consumption and breast cancer risk among BRCA1 mutation carriers. Cancer Epidemiol Biomarkers Prev 2007;16:912-6.
28. Ganmaa D, Willett WC, Li TY, et al. Coffee, tea, caffeine and risk of breast cancer: A 22-year follow-up. Int J Cancer 2008;122:2071-6.

29. Ishitani K, Lin J, Manson JE, et al. Caffeine Consumption and the Risk of Breast Cancer in a Large Prospective Cohort of Women. Arch Intern Med 2008;168:2022.

30. Larsson SC, Bergkvist L, Wolk A. Coffee and black tea consumption and risk of breast cancer by estrogen and progesterone receptor status in a Swedish cohort. Cancer Causes Control 2009;20:2039-44.

31. Bissonauth V, Shatenstein B, Fafard E, et al. Risk of Breast Cancer Among French-Canadian Women, Noncarriers of More Frequent $<$ I $>$ BRCA1 $/ 2</$ I $>$ Mutations and Consumption of Total Energy, Coffee, and Alcohol. Breast J 2009;15:S63-S71.

32. Wilson KM, Mucci LA, Cho E, et al. Dietary Acrylamide Intake and Risk of Premenopausal Breast Cancer. Am J Epidemiol 2009;169:954-61.

33. Boggs DA, Palmer JR, Stampfer MJ, et al. Tea and coffee intake in relation to risk of breast cancer in the Black Women's Health Study. Cancer Causes Control 2010;21:1941-8

34. Nilsson LM, Johansson I, Lenner P, et al. Consumption of filtered and boiled coffee and the risk of incident cancer: a prospective cohort study. Cancer Causes Control 2010;21:1533-44.

35. Bhoo Pathy N, Peeters P, van Gils C, et al. Coffee and tea intake and risk of breast cancer. Breast Cancer Res Treat 2010;121:461-7.

36. Li J, Seibold P, Chang-Claude J, et al. Coffee consumption modifies risk of estrogen-receptor negative breast cancer. Breast Cancer Res 2011;13:R49.

37. Fagherazzi G, Touillaud MS, Boutron-Ruault MC, et al. No association between coffee, tea or caffeine consumption and breast cancer risk in a prospective cohort study. Public Health Nutr 2011;14:1315-20.

38. Gierach GL, Freedman ND, Andaya A, et al. Coffee intake and breast cancer risk in the NIH-AARP diet and health study cohort.Int J Cancer 2012;131:452-60.

39. Mizoo T, Taira N, Nishiyama K, et al. Effect of lifestyle and single nucleotide polymorphisms on breast cancer risk: A case-control study in Japanese women. BMC Cancer 2013;13:565.

40. Hashibe M, Galeone C, Buys SS, et al. Coffee, tea, caffeine intake, and the risk of cancer in the PLCO cohort. Br J Cancer 2015;113:809-16.

41. Oh JK, Sandin S, Ström P, et al. Prospective study of breast cancer in relation to coffee, tea and caffeine in 
Sweden. Int J Cancer 2015;137:1979-89.

42. Harris HR, Bergkvist L, Wolk A. An estrogen-associated dietary pattern and breast cancer risk in the Swedish Mammography Cohort. Int J Cancer 2015;137:2149-54.

43. Bhoo-Pathy N, Peeters PHM, Uiterwaal CSPM, et al. Coffee and tea consumption and risk of pre- and postmenopausal breast cancer in the European Prospective Investigation into Cancer and Nutrition (EPIC) cohort study. Breast Cancer Res 2015;17:15.

44. Kotemori A, Ishihara J, Zha L, et al. Dietary acrylamide intake and risk of breast cancer: The Japan Public Health Center-based Prospective Study. Cancer Sci 2018;109:843-53.

45. Arthur R, Kirsh V, Rohan TE. Association between Dietary Energy Density and Risk of Breast, Endometrial, Ovarian, and Colorectal Cancer among Canadian Women. Cancer Epidemiol Biomarkers Prev 2018;27:338-41.

46. Yaghjyan L, Rich S, Mao L, et al. Interactions of coffee consumption and postmenopausal hormone use in relation to breast cancer risk in UK Biobank. Cancer Causes Control 2018;29:519-525.

47. El-Nabi SH, Dawoud GTM, El-Garawani I, et al. HPLC Analysis of Phenolic Acids, Antioxidant Activity and in vitro Effectiveness of Green and Roasted Caffea arabica Bean Extracts: A Comparative Study. Anticancer Agents Med Chem 2018;18:1281-8.

48. Romanos-Nanclares A, Sanchez-Quesada C, Gardeazabal I, et al. Phenolic Acid Subclasses, Individual Compounds, and Breast Cancer Risk in a Mediterranean Cohort: The SUN Project. J Acad Nutr Diet 2020;120:1002-15.e5.

49. Nikitina D, Chen Z, Vallis K, et al. Relationship between Caffeine and Levels of DNA Repair and Oxidative Stress in Women with and without a BRCA1 Mutation. J Nutrigenet Nutrigenomics 2015;8:174-84.

50. Kotsopoulos J, Eliassen AH, Missmer SA, et al. Relationship between caffeine intake and plasma sex hormone concentrations in premenopausal and postmenopausal women. Cancer 2009; 115:2765-74.

51. Fung TT, Schulze MB, Hu FB, et al. A dietary pattern derived to correlate with estrogens and risk of postmenopausal breast cancer. Breast Cancer Res Treat 2012;132:1157-62.

52. Sisti JS, Hankinson SE, Caporaso NE, et al. Caffeine, coffee, and tea intake and urinary estrogens and estrogen metabolites in premenopausal women. Cancer Epidemiol Biomarkers Prev 2015;24:1174-83.

53. Tworoger SS, Missmer SA, Barbieri RL, et al. Plasma sex hormone concentrations and subsequent risk of breast cancer among women using postmenopausal hormones. J Natl Cancer Inst 2005;97:595-602.

54. van Dyk M, Miners JO, Marshall JC, et al. Identification of the caffeine to trimethyluric acid ratio as a dietary biomarker to characterise variability in cytochrome $\mathrm{P} 450$ 3A activity. Eur J Clin Pharmacol 2019;75:1211-8.

55. Wierzejska R. Coffee consumption vs. cancer risk - a review of scientific data. Rocz Panstw Zakl Hig 2015;66:293-8.

56. Dashti SG, Simpson JA, Karahalios A, et al. Adiposity and estrogen receptor-positive, postmenopausal breast cancer risk: Quantification of the mediating effects of fasting insulin and free estradiol. Int J Cancer 2020;146:1541-52.

57. de Melo Pereira GV, de Carvalho Neto DP, Magalhaes Junior AI, et al. Chemical composition and health properties of coffee and coffee by-products. Adv Food Nutr Res 2020;91:65-96.

58. Atoum MF, Alzoughool F, Al-Hourani H. Linkage Between Obesity Leptin and Breast Cancer. Breast Cancer (Auckl) 2020;14:1178223419898458.

59. Visser E, Geleijnse JM, de Roos B. Inter-Individual Variation in Cancer and Cardiometabolic Health Outcomes in Response to Coffee Consumption: A Critical Review. Mol Nutr Food Res 2020;64:e1900479.

60. Baspinar B, Eskici G, Ozcelik AO. How coffee affects metabolic syndrome and its components. Food Funct 2017;8:2089-101.

61. Barone I, Giordano C, Bonofiglio D, et al. Leptin, obesity and breast cancer: progress to understanding the molecular connections. Curr Opin Pharmacol 2016;31:83-9.

62. Saxena NK, Taliaferro-Smith L, Knight BB, et al. Bidirectional crosstalk between leptin and insulin-like growth factor-I signaling promotes invasion and migration of breast cancer cells via transactivation of epidermal growth factor receptor. Cancer Res 2008;68:9712-22.

63. Yamashita K, Yatsuya H, Muramatsu T, et al. Association of coffee consumption with serum adiponectin, leptin, inflammation and metabolic markers in Japanese workers: a cross-sectional study. Nutr Diabetes 2012;2:e33.

Cite this article as: $\mathrm{Li} \mathrm{Y}, \mathrm{Ma} \mathrm{L}$. The association between coffee intake and breast cancer risk: a meta-analysis and dose-response analysis using recent evidence. Ann Palliat Med 2021;10(4):3804-3816. doi: 10.21037/apm-20-1962 